\section{Berlin and global warming policy}

SIR - Your leading article (Nature 374, 199-200; 1995) rightly emphasizes the importance of the global warming issue and the need for international negotiations to have "the whole world on side" both scientifically and so far as policy is concerned. We would suggest that one of the main reasons why global warming is being taken seriously by governments is due to the work of the Intergovernmental Panel on Climate Change (IPCC) which has provided effective, unbiased and widely available assessments of the science of climate change, its potential impact and possible adaptation and mitigation strategies. Your leading article argues, however, that the IPCC should be replaced in its function of giving scientific and technical advice by a body based on the model of the UN Scientific Committee on the Effects of Atomic Radiation (UNSCEAR). This view seems to be based on superficial knowledge of the IPCC reports, misunderstanding of what the Climate Convention (the FCCC) requires and ignorance of the modus operandi of the IPCC.

One reason that you cite is that the IPCC "reflects the weaknesses and vested interests of its sponsors" (what these are is not explained). We can categorically state that the IPCC determines its own programme of work and publishes its assessments with no interference from its sponsors, the World Meteorological Organization and the UN Environmental Programme.

A further reason you mention concerns the mode of working of IPCC. In fact IPCC carries out its work largely in the way you propose. The IPCC plenary (composed of government representatives) determines the scope of the reports, full-time staff is available in Geneva (for central coordination) and at the three IPCC working group secretariats. It has a large army of 'consultants' - leading members of the research community who donate their time and who are primarily responsible for drafting and reviewing the technical reports. Workshops and seminars are organized on important issues. The very wide participation by the scientific community in the preparation of the reports is one of the strengths of the IPCC process compared to one (as in UNSCEAR) where the report's preparation is in the hands of comparatively few. Scientists from developing countries are also included.

A further point you make is that the IPCC assessments are not "comprehensive or welcoming of contrary opinions". No convincing evidence is presented to support this. In fact the scope of the IPCC assessments is very broad and comprehensive. The reports cover all aspects of climate change including perturbations to the physical system, impact on both ecological and socio-economic systems, technological options for adaptation to climate change and for the mitigation of emissions, geo-engineering options (which are not always the "crackpot ideas" you suggest but which deserve serious analysis) and methodologies for use by countries in developing their inventories of greenhouse gas emissions and their potential impact/response options. The Second Assessment Report currently being prepared by the three working groups will contain nearly 60 chapters.

Regarding contrary opinions, the review process undertaken by IPCC specifically addresses conflicting scientific opinion and ensures that these are properly exposed and represented in the statements of uncertainty. A particular example quoted in the leading article concerns the role of water vapour which, because of its importance as a greenhouse gas, is crucial in any assessment of global warm. ing. It is stated that water vapour (especially upper level water vapour and ice) is neglected in climate models. This is simply untrue. As is evidenced in all of the IPCC reports, models that have been available during the past five years include comprehensive descriptions of all phases of water and of their role in cloud formation. Further, because of some significant controversy over the magnitude and the sign of water vapour feedback (associated with the 'air conditioner' idea mentioned in your leading article) the IPCC 1992 report discussed the role of upper tropospheric water vapour in some detail. The considerable uncertainty that still exists about the magnitude of the feedback is reflected in the uncertainty range given in the IPCC reports for the magnitude of the expected global warming.

The IPCC is a relatively young institution and a great deal of learning has taken place during the first five years of operation. We are open to further improvements. But the structure and procedures of the IPCC have allowed the scientific and technical community to be responsive to governments while pursuing what it believes to be scientifically important.

The IPCC is charged with providing scientific and technical information to the public and to policy-makers but not to propose action programmes. That is for the political process. For instance, whether to act soon or not is a political decision that must be made in the light of careful analysis of the inertia of both the

Letters submitted for Correspondence should be typed, double-spaced, on one side of the paper only. global environmental system and the socio-economic system, as well as an evaluation of the prospects for developing and applying technologies that permit continued economic growth with lower rates of greenhouse gas emissons. Such analyses are provided in the IPCC assessments.

The IPCC process has two main strengths. First, in its assessments it has succeeded in involving a very large proportion of the active scientists (many of them world leaders) working in the field over a wide range of countries. IPCC reports have therefore achieved a large degree of ownership by the worldwide scientific community. In a field as complex and controversial as global warming, assessments by smaller groups of scientists would not carry the same degree of acceptance. Second, because IPCC is intergovernmental and involves government scientists in its approval process, it has also been recognized as their prime source of information. This is absolutely essential. To move the policy debate forward requires the broad acceptance by governments of the underlying science. Any body chosen to advise the UN Framework Convention on Climate Change must ensure that these two strengths are maintained.

\section{Bert Bolin}

(Chairman)

\section{John Houghton}

(Co-chairman of Working Group I)

Intergovernmental Panel

on Climate Change,

Meteorological Office,

Hadley Climate Centre,

London Road,

BracknellRG12 2SY, UK

\section{Sounds right}

SIR - The scholarly analysis of Katsikis and Leben (Nature 374, 670; 1995) seems to have turned the tide Funder's way on apoptosis.

We write to point out that he unnecessarily weakened his own case in his opening letter (Nature 371, 98; 1994) by implying that Italians would not pronounce the second $\mathrm{p}$ when they say apoptosis. Surrounded as we are by Italians working on apoptosis, we can assure him they do.

The examples Funder cited were the Italian equivalents for pterodactyl and helicopter, in which he claimed the $p$ is neither written or sounded. He was right about helicopter (elicottero), but wrong about pterodactyl (pterodactilo). The $\mathrm{p}$ is written and, like anything written in Italian, it is sounded.

\section{John Ross}

\section{David Burr}

Istituto di Neurofisiologia de/ CNR,

ViaSZeno 56 ,

Pisa 56100, Italia

NATURE - VOL 375 - 18 MAY 1995 